\title{
Excellent ductility and serration feature of metastable CoCrFeNi high-entropy alloy at extremely low temperatures
}

\author{
Junpeng Liu ${ }^{1,6 \dagger}$, Xiaoxiang $\mathrm{Guo}^{2 \dagger}$, Qingyun $\operatorname{Lin}^{3 \dagger}$, Zhanbing $\mathrm{He}^{1 \dagger}$, Xianghai $\mathrm{An}^{3}$, Laifeng $\mathrm{Li}^{4}$,

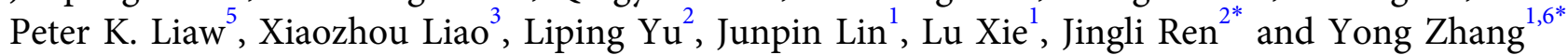

\begin{abstract}
Seldom could metals and alloys maintain excellent properties in cryogenic condition, such as the ductility, owing to the restrained dislocation motion. However, a face-centered-cubic (FCC) CoCrFeNi highentropy alloy (HEA) with great ductility is investigated under the cryogenic environment. The tensile strength of this alloy can reach a maximum at $1,251 \pm 10 \mathrm{MPa}$, and the strain to failure can stay at as large as $62 \%$ at the liquid helium temperature. We ascribe the high strength and ductility to the low stacking fault energy at extremely low temperatures, which facilitates the activation of deformation twinning. Moreover, the FCC $\rightarrow$ HCP (hexagonal close-packed) transition and serration lead to the sudden decline of ductility below $77 \mathrm{~K}$. The dynamical modeling and analysis of serrations at 4.2 and $20 \mathrm{~K}$ verify the unstable state due to the FCC $\rightarrow \mathrm{HCP}$ transition. The deformation twinning together with phase transformation at liquid helium temperature produces an adequate strain-hardening rate that sustains the stable plastic flow at high stresses, resulting in the serration feature.
\end{abstract}

Keywords: high-entropy alloy, liquid-helium temperature, twinning, phase transition, serration feature

\section{INTRODUCTION}

Materials with high ductility at low temperatures (LT) are desired for cryogenic applications in the space exploration, superconducting devices, nuclear reactors, and storage of cryogens. Face-centered-cubic (FCC) alloys are promising in this regard, as they do not exhibit an obvious ductile-to-brittle transition at LT [1]. A popular example of such alloys in use is 316 stainless steel (SS) $[2,3]$ : at the liquid-nitrogen temperature, 316 SS can sustain a uniform elongation and plastic strain to failure similar to those at room temperature (RT), in some cases even larger, while the strength is also significantly high. This high ductility, due to a high dislocation storage rate and strain-hardening capability at LT, allows the large uniform deformation without strain localization [4]. However, in cryogenic environments, with the strength more than $1 \mathrm{GPa}$, rare metals and alloys can be elongated to failure larger than $50 \%$. At liquid-helium temperature, the strain-hardening rate is insufficiently high to keep up with the fast rising flow stress, like Considere criterion at a smaller strain. It is challenging to retain the high ductility from RT to LT.

Recently, Gludovatz et al. [5] found that the FCC CrMnFeCoNi high-entropy alloy (HEA) possesses strength, ductility, and fracture toughness that are similar to, if not better than, the best 316 SS at the liquidnitrogen temperature. Later on, they reported that the CrCoNi medium-entropy alloy is even tougher [6]. They suggested that the additional twinning mechanism contributes to the excellent stain hardening at LT. The low stacking fault energy (SFE) of these alloys and, hence, the easier activation of deformation twinning (DT) is a key factor promoting the strain hardening and ductility

\footnotetext{
${ }^{1}$ State Key Laboratory for Advanced Metals and Materials, University of Science and Technology Beijing, Beijing 100083, China

${ }^{2}$ School of Mathematics and Statistics, Zhengzhou University, Zhengzhou 450001, China

${ }^{3}$ School of Aerospace, Mechanical \& Mechatronic Engineering, The University of Sydney, Sydney NSW 2006, Australia

${ }^{4}$ Key laboratory of Cryogenics, Technical Institute of Physics and Chemistry, Chinese Academy of Sciences, Beijing 100190, China

${ }^{5}$ Department of Materials Science and Engineering, The University of Tennessee, Knoxville, TN 37996, USA

${ }^{6}$ Beijing Advanced Innovation Center for Materials Genome Engineering, University of Science and Technology Beijing, Beijing 100083, China

† These authors contributed equally to this work.

* Corresponding authors (emails: drzhangy@ustb.edu.cn (Zhang Y); renjl@zzu.edu.cn (Ren J))
} 
$[7,8]$. However, it is indicated that DT is not dominant in the standard tensile test of these alloys at RT and even at the liquid-nitrogen temperature [9], and the volume fraction of deformation twins is rather low, possibly because the sample-wide stress is not more than the critical stress needed for DT [10]. Profuse DT is only near the crack tip, where stresses concentrate.

The above discussion prompts us to explore a different scenario where DT $[11,12]$ can be promoted: deformation at extremely low temperatures, where the deformation stress is expected to be very high even in a normal tensile test at ordinary laboratory strain rates.

Owing to the easy oxidization of manganese, the $\mathrm{CoCrFeNi}$ equiatomic HEA was produced, and just like the CoCrFeNiMn alloy, it exhibited excellent mechanical properties and great cryogenic performance [13-16]. However, most studies focus on the performances of HEAs above $77 \mathrm{~K}$ [17-21], and no one cares about the service performance, especially the tensile properties of this alloy, when further decreasing the temperature. In this paper, we examine the strength/ductility behavior of a $\mathrm{CoCrFeNi}$ equiatomic HEA in tensile tests from RT down to liquid-helium temperature. If DT does become overwhelmingly dominant, how much strength, strain hardening, and ductility can HEAs achieve, and could the contribution from the considerable martensitic transformation as in the case of stainless steels occur? These are the critical questions to be addressed in the present work. Furthermore, the serration is detected at the liquidhelium temperatures, and the dynamical modelling and analysis of them are provided to reveal whether there is any difference in this condition.

\section{EXPERIMENTAL SECTION}

\section{Sample preparation and mechanical testing}

With the nominal composition of the quaternary
CoCrFeNi HEA [22] (25:25:25:25 at.\%, purity> 99.9 wt.\%), a $3 \mathrm{~kg}$ alloy ingot was melted under highpurity argon atmosphere in a vacuum induction levitation melting furnace [23]. The ingot was melted three times to ensure the chemical homogeneity, and cooled naturally to $\mathrm{RT}$. Then the as-cast round ingot with a diameter of $90 \mathrm{~mm}$ was homogenized by annealing for $20 \mathrm{~h}$ at $1,373 \mathrm{~K}$, and hot-forged at $1,473 \mathrm{~K}$ more than six times to ensure the chemical homogeneity and to eliminate the casting flaws, and then cooled to RT in air. The final dimensions are $30 \mathrm{~mm}$ in thickness and $60 \mathrm{~mm}$ in width (a total reduction in thickness of about 62.5\%). We milled away the surface scale to resist oxidation during processing.

Rectangular dog-bone shaped tensile specimens with a gauge length of $15 \mathrm{~mm}$ were machined from the ingot by electrical discharge machining (EDM). Both sides of the specimen were ground using the $\mathrm{SiC}$ paper, resulting in a final thickness of about $1.7 \mathrm{~mm}$ and a gauge width of about $3 \mathrm{~mm}$. Vickers microhardness indents (300 g load) were made to define the gauge length for strain measurements after fracture. All the samples were tested by a MTS-SANS CMT5000 universal testing machine at the Key Laboratory of Cryogenics, Technical Institute of Physics and Chemistry, Chinese Academy of Sciences (TIPC, CAS), at a strain rate of $10^{-3} \mathrm{~s}^{-1}$. Tensile tests were performed at four different temperatures, $293 \mathrm{~K}$ (room temperature), $200 \mathrm{~K}, 77 \mathrm{~K}$ (liquid nitrogen temperature), and $4.2 \mathrm{~K}$ (liquid helium temperature). For each temperature, at least three samples were tested. The fracture surfaces were examined, using scanning-electron microscopy (SEM). Additional tensile experiments were carried out at 50 and $20 \mathrm{~K}$, with five samples tested for each temperature.

Young's modulus $(E)$, yield strength $\left(\sigma_{\mathrm{y}}\right)$, and ultimate tensile strength $\left(\sigma_{\mathrm{u}}\right)$ obtained from the engineering stressstrain curve are listed in Table 1. The plastic strain was

Table 1 Mechanical properties of the CoCrFeNi high-entropy alloy at different temperatures

\begin{tabular}{|c|c|c|c|c|c|c|}
\hline \multirow{2}{*}{ Tension properties } & \multicolumn{6}{|c|}{ Temperature } \\
\hline & $293 \mathrm{~K}$ & $200 \mathrm{~K}$ & $77 \mathrm{~K}$ & $50 \mathrm{~K}^{\star}$ & $20 \mathrm{~K}^{*}$ & $4.2 \mathrm{~K}$ \\
\hline$\sigma_{\mathrm{y}}(\mathrm{MPa})$ & 446 & 488 & 590 & - & - & 680 \\
\hline$\sigma_{\mathrm{u}}(\mathrm{MPa})$ & 664 & 790 & 1,070 & $1,152 \pm 8$ & $1,240 \pm 40$ & $1,251 \pm 10$ \\
\hline$\varepsilon_{\mathrm{f}}$ & $63 \%$ & $72 \%$ & $78 \%$ & $68.6 \% \pm 3.3 \%$ & $62 \% \pm 0.6 \%$ & $61.6 \% \pm 1.6 \%$ \\
\hline$E(\mathrm{GPa})$ & 189 & 194 & 204 & - & - & 221 \\
\hline $\begin{array}{l}\text { Work-hardening } \\
\text { capability, } \sigma_{\mathrm{u}}-\sigma_{\mathrm{y}}(\mathrm{MPa})\end{array}$ & 218 & 302 & 480 & - & - & 580 \\
\hline
\end{tabular}

${ }^{*}$ Tensile tests at 50 and $20 \mathrm{~K}$ were performed without the extensometer. As a result, the yield strength and Young's modulus were not determined accurately, while the ultimate tensile strength and the failure strain could be measured exactly. 
recorded using an extensometer. The elongation to failure, $\varepsilon_{\mathrm{f}}$, was determined from the indents under an optical microscope.

\section{Microstructure characterization}

The X-ray diffraction (XRD) was carried out with $\mathrm{Cu} \mathrm{Ka}$ radiation, and SEM images were obtained in a Zeiss Supra55 machine. Before and after tensile tests, a thin sheet with a thickness of about $500 \mu \mathrm{m}$ was machined from the samples and ground down to a thickness of $100 \mu \mathrm{m}$ using the fine SiC paper. Discs with a diameter of $3 \mathrm{~mm}$ were punched out of the foil, then mechanically ground to a thickness of about $45 \mu \mathrm{m}$, and twin-jet polished, using a mixed solution of $\mathrm{HNO}_{3}: \mathrm{CH}_{4} \mathrm{O}=1: 4$ (volume fraction) for the original structure characterization. Transmission electron microscopy (TEM) samples of the deformed samples were carefully extracted from the necking area and ground down to $35 \mu \mathrm{m}$ with the fine $\mathrm{SiC}$ paper, and then thinned using the ion-milling till perforation. TEM and high-resolution scanning-transmission-electron-microscopy (STEM) investigations were conducted with a Tecnai $\mathrm{G}^{2}$ F30 S-TWIN microscope.

\section{Dynamical modeling and analyses for the serrated flow}

\section{Fractal dimension}

Fractal dimension is introduced to quantify the selfsimilarity of the serrated flow stress. According to the box-counting method [24-26], it needs at least $N(l)$ boxes with the box size of $l$ to cover the total data set. Changing the box size, $l$, one can obtain a series of $N(l)$, and then fit $[l, N(l)]$ in a double logarithmic plot, the slope of this fitting curve is the fractal dimension $(D)$.

$D=-\lim _{l \rightarrow 0} \frac{\ln N(l)}{\ln l}$.

\section{Phase space reconstruction}

The phase space reconstruction method by the delaycoordinate technique was used to reveal the hidden order of the serration [27-29]. Note that the stress signals at the stage of plastic deformation are $\left\{\sigma_{1}, \sigma_{2}, \sigma_{3}, \ldots, \sigma_{N}\right\}$. According to the embedding dimension theorem developed by Taken et al. [30,31], the stress signals can be embedded into an $m$-dimensional phase space. In the phase space, the $i$ th point is given as:

$$
\begin{aligned}
& Y(i)=\left(\sigma_{i}, \sigma_{i+\tau}, \sigma_{i+2 \tau}, \ldots, \sigma_{i+(m-1) \tau}\right), \\
& i=1,2, \ldots, N-(m-1) \tau,
\end{aligned}
$$

where $\tau$ is the time delay, $m$ is the embedding dimension, and $N$ is the length of stress signals. To reconstruct a phase space from a time series, the suitable time delay and embedding dimension are indispensable. Here the mutual information technique [32] and Cao method [33] were used to calculate the appropriate time delay and embedding dimension, respectively.

The mutual information of the stress signals, $\left\{\sigma_{i}\right\}$, is defined as a function of the time delay:

$I(\tau)=\sum_{i=1}^{N-\tau} P\left(\sigma_{i}, \sigma_{i+\tau}\right) \log _{2} \frac{P\left(\sigma_{i}, \sigma_{i+\tau}\right)}{P\left(\sigma_{i}\right) P\left(\sigma_{i+\tau}\right)}$,

where $P\left(\sigma_{i}\right), P\left(\sigma_{i+\tau}\right)$, and $P\left(\sigma_{i}, \sigma_{i+\tau}\right)$ are the probabilities and joint probability of $\sigma_{i}$ and $\sigma_{i+\tau}$ appearing in the signals. When $I(\tau)$ first reaches its local minimum, the corresponding time delay, $\tau_{0}$, is a suitable value $[29,32]$.

An $m$-dimensional point in the reconstructed phase space is defined as Equation (2), which denotes its nearest neighbor point (in the sense of Euclid norm) as

$Y^{*}(i)=\left(\sigma_{i}^{*}, \sigma_{i+\tau}^{*}, \sigma_{i+2 \tau}^{*}, \ldots, \sigma_{i+(m-1) \tau}^{*}\right)$,

and the distance of these two points is $d^{m}(i)=\| Y(i)-$ $Y^{*}(i) \|_{(m)}$. If the embedding dimension increases to $m+1$, the distance becomes $d^{m+1}(i)=\left\|Y(i)-Y^{*}(i)\right\|_{(m+1)}$, and the mean value of the distance variation from $m$ to $m+1$ is

$D(m)=\frac{1}{N-(m-1) \tau} \sum_{i=1}^{N-(m-1) \tau} \frac{d^{m+1}(i)}{d^{m}(i)}$.

Let

$E_{1}(m)=\frac{D(m+1)}{D(m)}$ and $E_{2}(m)=\frac{D^{*}(m+1)}{D^{*}(m)}$,

where

$D^{*}(m)=\frac{1}{N-(m-1) \tau} \sum_{i=1}^{N-(m-1) \tau}\left|\sigma_{i+m \tau}-\sigma_{i+m \tau}^{*}\right|$.

$E_{1}(m)$ reflects the change in the mean value of the distance fluctuation, and $E_{2}(m)$ is used to distinguish the deterministic signals from stochastic signals. It indicates that the appropriate embedding dimension, $m_{0}$, is advisable when $E_{1}(m)$ tends to be steady and $E_{2}(m)$ approaches 1 [33].

\section{Largest Lyapunov exponent}

The largest Lyapunov exponent $(\lambda)$ is a significant parameter for characterizing the dynamical behaviors of the phase space $[27,28]$. The largest Lyapunov exponent quantifies the rate of the divergence of the trajectories in the phase space. In the reconstructed phase space, the largest Lyapunov exponent is calculated by the Wolf's method [34].

An initial point and its nearest neighbor point in the phase space are given as $Y\left(i_{0}\right)$ and $Y_{0}^{*}\left(i_{0}\right)$, and the distance between these two points is $d_{0}=\left|Y\left(i_{0}\right)-Y_{0}{ }_{0}\left(i_{0}\right)\right|$. Tracking 
the evolution from $i_{0}$ to $i_{1}$, then, $Y\left(i_{0}\right)$ evolves into $Y\left(i_{1}\right)$, $Y_{0}^{*}\left(i_{0}\right)$ reaches $Y_{0}^{*}\left(i_{1}\right)$, and the distance, $d_{0}$, changes to $d_{0}=\left|Y\left(i_{1}\right)-Y_{0}^{*}\left(i_{1}\right)\right|$. The point, $Y_{0}^{*}\left(i_{1}\right)$, may not be the nearest neighbor point of $Y\left(i_{1}\right)$. Hence, the nearest neighbor point of $Y\left(i_{1}\right)$ is reselected as $Y^{*}{ }_{1}\left(i_{1}\right)$. The distance between $Y\left(i_{1}\right)$ and $Y^{*}{ }_{1}\left(i_{1}\right)$ becomes $d_{1}=\mid Y\left(i_{1}\right)$ $Y^{*}{ }_{1}\left(i_{1}\right) \mid$. The angle between $d_{0}$ and $d_{1}$ is set as small as possible to reduce the influence on the orbit evolution, when we choose the nearest neighbor point. Then tracking the evolution to obtain $d_{1}$, and repeating above process until the end of time series, we can determine the number of these iterations, $K$. Thus, we have

$d_{k}=\left|Y\left(i_{k}\right)-Y_{k}^{*}\left(i_{k}\right)\right|$ and $d_{k}=\left|Y\left(i_{k+1}\right)-Y_{k-1}^{*}\left(i_{k+1}\right)\right|$,

$k=0,1,2, \ldots, K$.

The largest Lyapunov exponent is defined as:

$\lambda=\frac{1}{i_{K}-i_{0}} \sum_{k=0}^{K} \ln \frac{d^{\prime}{ }_{k}}{d_{k}}$.

A positive $\lambda$ would suggest that the dynamics of the system follows the chaotic behavior, which means that the system is under an unstable state, while a negative $\lambda$ indicates that the system will evolve into a stable state.

\section{RESULTS}

\section{Crystal structure}

The as-prepared HEA has nearly equiaxed grains with a mean size of about $13 \mu \mathrm{m}$, as shown in Fig. 1a. It is a single-phase FCC solid solution, as indicated by XRD pattern shown in Fig. 1b. The bright-field TEM image in Fig. $1 \mathrm{c}$ represents the dislocations and $\{111\}$ twins (see the selected-area electron-diffraction (SAED) pattern in Fig. 1d), as the sample was hot-rolled.

\section{Mechanical properties}

The measured uniaxial tension engineering stress-strain curves of the CoCrFeNi HEA at 293, 200, 77, 50, 20 and $4.2 \mathrm{~K}$ are shown in Fig. 2a, with the images of the samples before and after the test (the lower right corner in Fig. 2a). Numerous serrations appear in the stress-strain curves at $4.2 \mathrm{~K}$ (e.g., an enlarged view in the upper-left corner of Fig. 2a), accompanied by the audible click with every stress drop. This unique phenomenon is not obvious in the beginning stage (small strains) of the plastic deformation at $20 \mathrm{~K}$ (see Fig. S1).

The yield strength and ultimate tensile strength (UTS) are increased gradually with temperature decrease (Fig. 2b). At $77 \mathrm{~K}$, their values are 590 and 1,070 MPa, respectively. Meanwhile, the percent elongation also increases from $63 \%$ at RT to $78 \%$ at $77 \mathrm{~K}$ (Table 1).

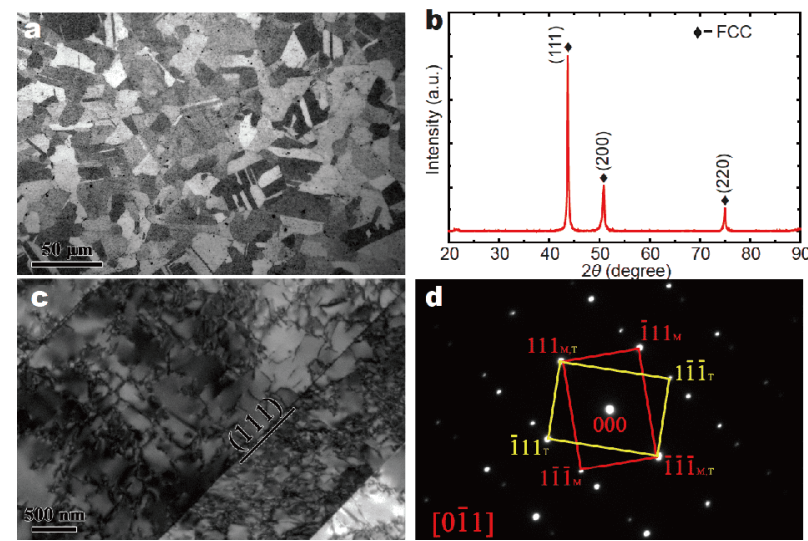

Figure 1 Typical microstructure of the CoCrFeNi HEA. (a) Optical metallographic image of the sample, displaying roughly equiaxed grains with an average size of $13 \mu \mathrm{m}$. (b) XRD pattern shows the alloy has a single FCC phase. (c) TEM image and electron-diffraction patterns (d), presenting high-density dislocations and some twins in the original sample.

The CoCrFeNi HEA exhibits an excellent combination of strength and ductility even at $4.2 \mathrm{~K}$, where the engineering yield strength and UTS further elevate to 680 and 1,260 MPa, respectively. Meantime, the elongation of this alloy is $69 \%$ at $50 \mathrm{~K}$, and remains as large as about $62 \%$ at 20 and $4.2 \mathrm{~K}$ (Table 1). All the samples show pronounced strain hardening after yielding (Fig. 2a, c). The strain-hardening rate, $\Theta=\mathrm{d} \sigma / \mathrm{d} \varepsilon$, is sustained at a high level to similarly large strains, preventing the necking. Even the CoCrFeNi HEA exhibits excellent combination of properties, and the elongation declines sharply below $77 \mathrm{~K}$ (see Fig. 2b), which would be discussed later in this article.

The UTS versus the elongation at $4.2 \mathrm{~K}$ for different cryogenic materials in Fig. 3 clearly shows that the CoCrFeNi HEA has an outstanding combination of strength and ductility. The UTS of this alloy is higher than those of most conventional cryogenic materials, such as aluminum alloys [1], copper alloys $[11,35,36]$, and comparable to the strength of some stainless steels [37] or titanium alloys [3]. Meanwhile, the elongation of the $\mathrm{CoCrFeNi}$ alloy at $4.2 \mathrm{~K}$ exceeds all of the mentioned cryogenic materials at the strength level above $1 \mathrm{GPa}$.

\section{Dynamics of serration}

Phase space reconstruction method [30,31] is introduced to investigate the dynamical behavior of the serrated flow. Time delay and embedding dimension are two necessary variables to reconstruct this phase space. The time delay can be obtained from the mutual information method [32], and the embedding dimension is calculated by Cao's 

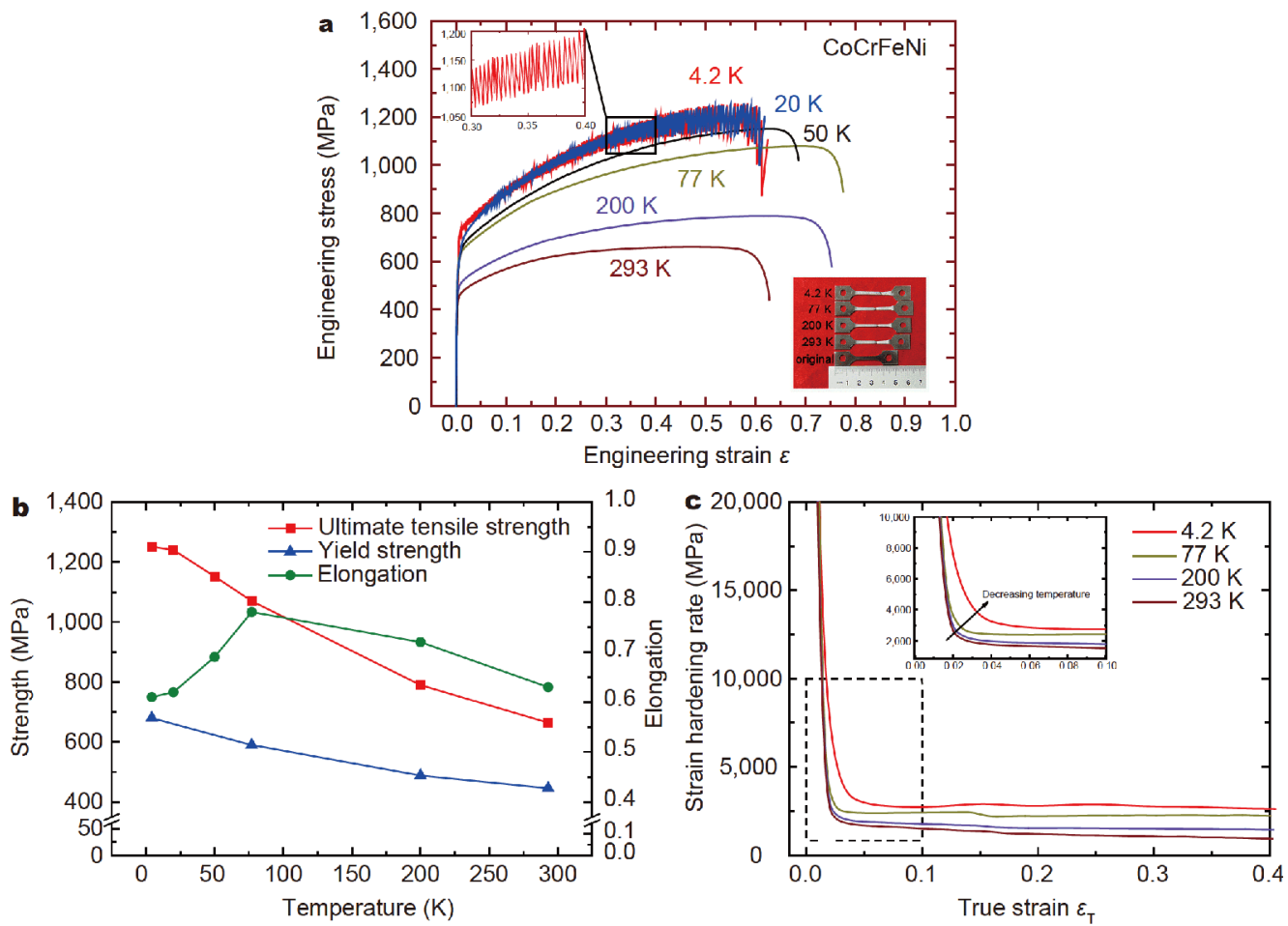

Figure 2 Tensile properties of the CoCrFeNi alloy at different temperatures. (a) Engineering stress-strain curves and photograph of the dog-boneshaped samples, before and after tensile tests. The enlarged stress-strain curve at $4.2 \mathrm{~K}$ is displayed in the inset. This HEA exhibits increasing strength with decreasing temperature, and the ductility reaches the maximum at $77 \mathrm{~K}$, as shown in (b). In addition, at $20 \mathrm{~K}$ and below, the stress drop occurs in the tensile curve. Moreover, the ductility of this alloy decreases abruptly below $77 \mathrm{~K}$. (c) $\Theta v s$. true strain $\left(\varepsilon_{\mathrm{T}}\right)$ curves at different temperatures. Inset: an enlarged view of the black-dashed box. The strain-hardening rate is adequate, including at $4.2 \mathrm{~K}$, to sustain large true strains before necking instability.

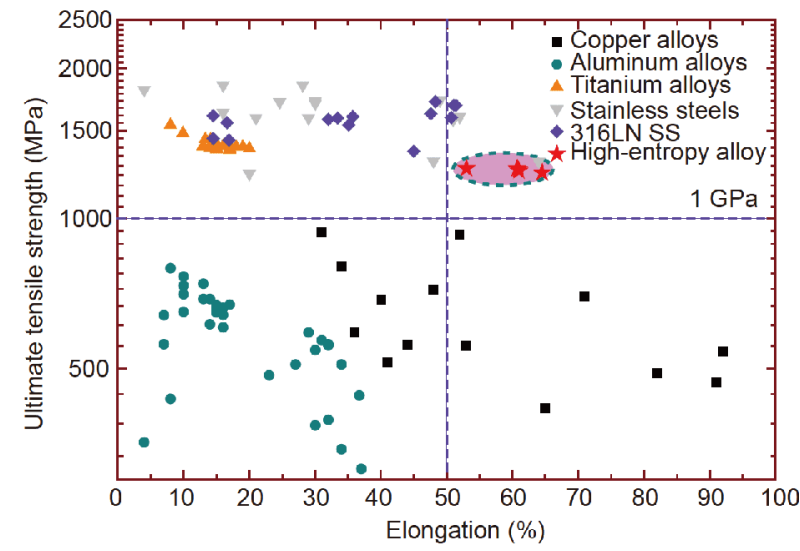

Figure 3 Ashby map showing the UTS versus percent elongation to failure for HEAs, compared with a wide range of cryogenic materials at $4.2 \mathrm{~K}$. The oval-shaped pink region represents the HEA, showing its excellent combination of high strength and great ductility.

method [33]. The mutual information, $I(\tau)$, as a function of time delay, $\tau$, for the serration at $4.2 \mathrm{~K}$ and $20 \mathrm{~K}$ are shown in Fig. 4a. We define the $E_{1}(m)$ and $E_{2}(m)$ to reflect the change of the mean distance fluctuation and distinguish the deterministic signals from stochastic signals, respectively. Fig. $4 \mathrm{~b}$ gives $E_{1}(m)$ and $E_{2}(m)$ as a function of the embedding dimension, $m$, at $4.2 \mathrm{~K}$ and $20 \mathrm{~K}$. The suitable time delay, $\tau_{0}$, and suitable embedding dimension, $m_{0}$, are listed in Table 2 . Then, by those two defined variables, the serration can be embedded into the $m_{0}$-dimensional reconstructed phase space. After reconstructing the phase space from the serrated stress signal, the largest Lyapunov exponent is calculated (see all the details in EXPERIMENT SECTION). Both the largest Lyapunov exponents at 4.2 and $20 \mathrm{~K}$ are positive. Yet the value at $20 \mathrm{~K}$ is smaller than that at $4.2 \mathrm{~K}$ (see details in Table 2).

\section{Structural characterization of the deformed samples}

Necking eventually occurs at all temperatures (Fig. S2). The ductile nature of the fracture is clearly verified by the typical dimple rupture. The SEM images of the fracture surfaces after the tensile tests at different temperatures are shown in Fig. 5. Abundant dimples from the samples tested at 293 and $200 \mathrm{~K}$ (Fig. 5a, b) have a size ranging from micrometers $(1-10 \mu \mathrm{m})$ to nanometer. When 

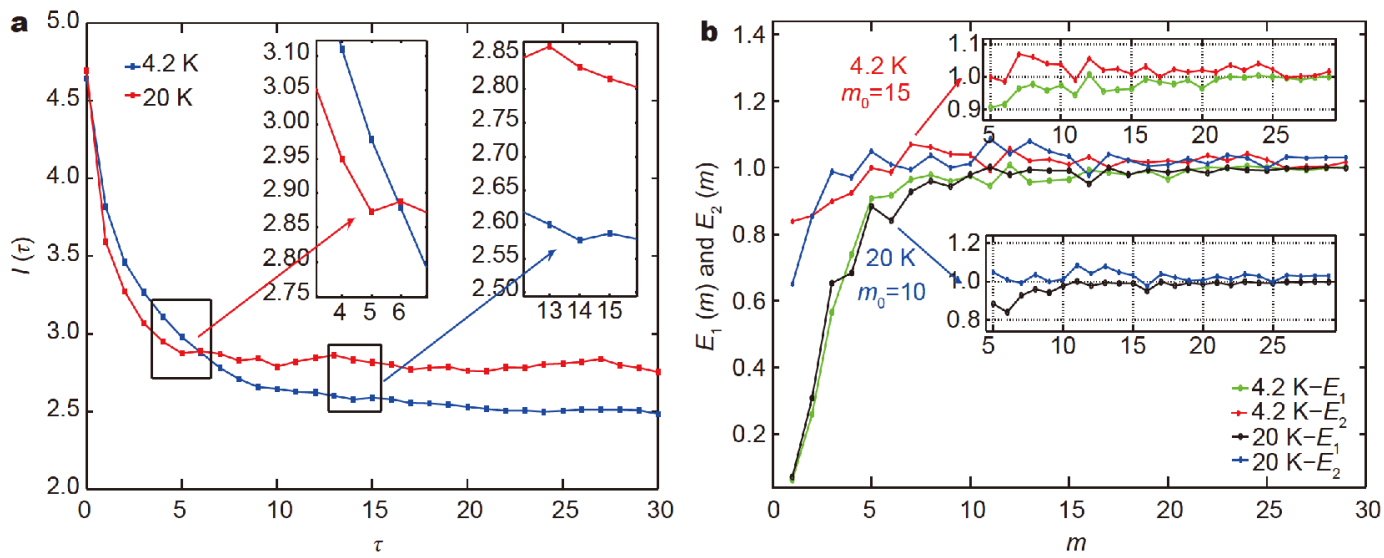

Figure 4 The dynamic analysis of the serration feature. (a) The mutual information, $I(\tau)$, as a function of time delay, $\tau$, for the serration at 4.2 and $20 \mathrm{~K}$. The insets show the magnified curves. When $I(\tau)$ first reaches its local minimum, the corresponding time decay, $\tau$, is the suitable value, $\tau_{0}$ [32]. (b) $E_{1}(m)$ and $E_{2}(m)$ as a function of the embedding dimension, $m$, at 4.2 and $20 \mathrm{~K}$. The inset gives a clear view of the state at 4.2 and $20 \mathrm{~K}$, respectively. $E_{1}(m)$ reflects the change in the mean value of the distance fluctuation, and the $E_{2}(m)$ is used to distinguish the deterministic signals from stochastic signals. When $E_{1}(m)$ tends to be steady and $E_{2}(m)$ approaches 1 , the appropriate embedding dimension, $m_{0}$, is obtained [33].

Table 2 The relevant parameters of the serrations at 4.2 and $20 \mathrm{~K}$

\begin{tabular}{ccccc}
\hline \multirow{2}{*}{ Temperature } & \multicolumn{3}{c}{ Parameter } \\
\cline { 2 - 5 } & Fractal dimension, $D$ & Suitable time delay, $\tau_{0}$ & Suitable embedding dimension, $m_{0}$ & Largest Lyapunov exponent, $\lambda$ \\
\hline $20 \mathrm{~K}$ & 1.22 & 5 & 10 & 0.001 \\
$4.2 \mathrm{~K}$ & 1.23 & 14 & 15 & 0.050 \\
\hline
\end{tabular}

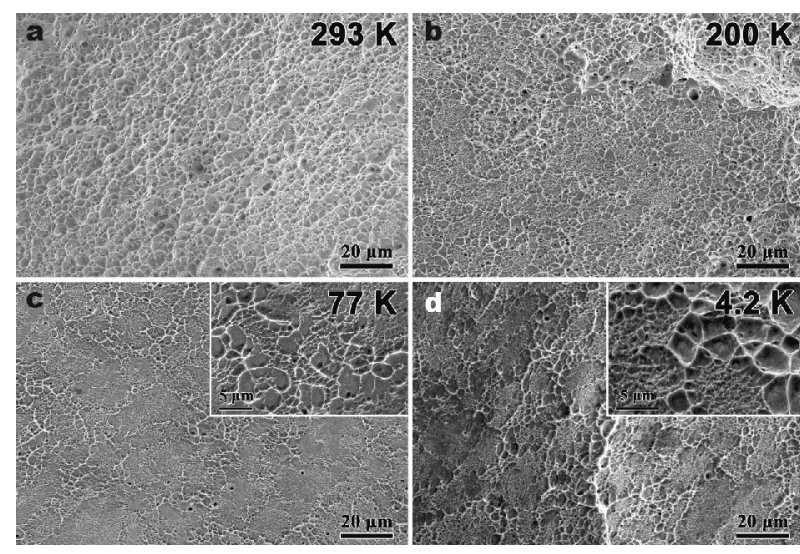

Figure 5 SEM images of fracture surfaces of the CoCrFeNi samples after the tensile tests at 293 (a), 200 (b), 77 (c), and $4.2 \mathrm{~K}$ (d), respectively. It shows a totally ductile fracture with a plenty of micrometersized or nanometer-sized dimples. The extent of micrometer dimples decreases with the temperature decreasing to $77 \mathrm{~K}$, but increases at $4.2 \mathrm{~K}$, consistent with the ductility (elongation failure) observed in tensile tests. A similar trend of the variation of elongation with the average dimple diameter was also reported for austenitic stainless steel [38].

decreasing the temperature to 77 and $4.2 \mathrm{~K}$, the number of micrometer-scale dimples is reduced, while more nanoscale ones (inset in Fig. 5c, d) appear. The work hardening, represented by the difference between the UTS and yield strength, $\left(\sigma_{\mathrm{u}}-\sigma_{\mathrm{y}}\right)$, is obviously increasing with decreasing temperature, and particularly large at the liquid-helium temperature, see details in Table 1.

Fig. 6 shows a typical microstructure of the sample after the tensile test at $4.2 \mathrm{~K}$. The grains are filled with high density lamellar structures (Fig. 6a, b), which are verified as $\{111\}$ twins from SAED patterns in Fig. $6 \mathrm{c}, \mathrm{f}$. The twins at nanoscale have the thickness ranging from 10 to $200 \mathrm{~nm}$. They reside within the larger annealing twins, which are present in the original sample before the tensile test, and sometimes penetrate across the pre-existing twin boundaries, as seen in Fig. $6 \mathrm{~d}$. The twins in each grain extend along two directions differing by $60^{\circ}$, resulting in many intersections of twin boundaries and enclosed nanoscale domains, Fig. 6e. In addition, the FCC $\rightarrow \mathrm{HCP}$ transition occurs at $4.2 \mathrm{~K}$, as shown in Fig. $6 \mathrm{~g}-\mathrm{i}$, which would be discussed in the following section.

\section{DISCUSSION}

Temperature dependence and the strain-hardening effects The "stronger and more ductile with decreasing temperature" trend (see Fig. 2b) is in accordance with 

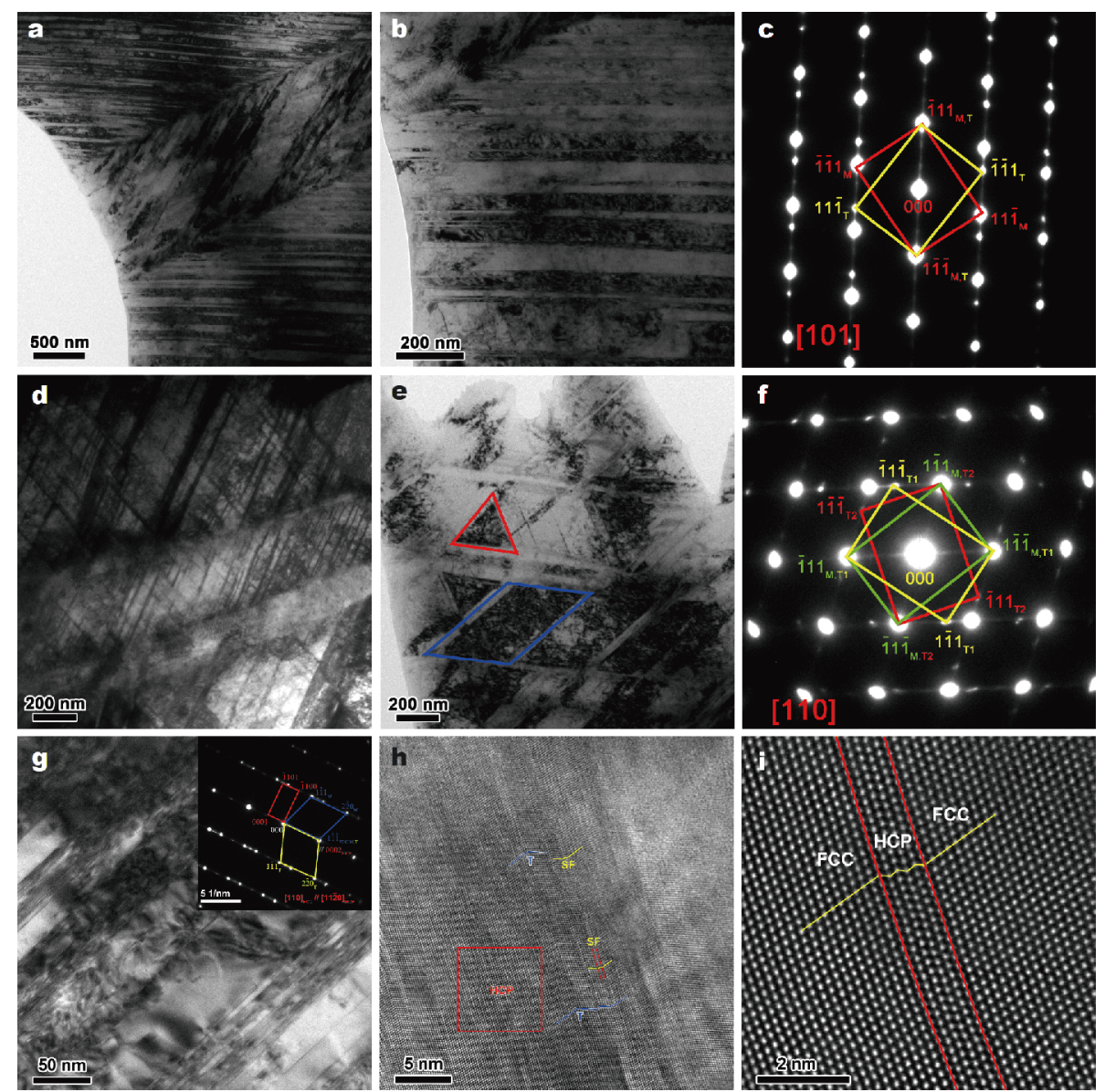

Figure 6 TEM and high-resolution STEM images of the CoCrFeNi sample with nanoscale twins and HCP phases after the tensile test at the liquidhelium temperature. (a) TEM image of deformation twins. (b) A close-up TEM observation of (a), and the SAED pattern (c), indicating that the typical deformation twins are parallel to each other on $\{111\}$ planes. (d) TEM image and the electron-diffraction patterns in (f), showing that twins in two orientations intersect each other. (e) The blue parallelogram and the red triangle present different morphologies due to intersecting twins. All the TEM images indicate that high-density nano-twins drastically refine the grains. (g) Bright-field TEM image with SAED patterns of $[110]_{\mathrm{FCC}} \|[11 \overline{2} 0]_{\mathrm{HCP}}$ showing the FCC twinning and HCP phase in the sample. (h) High-resolution STEM image containing the HCP stacking, stacking fault [SF], and nano-twins $[\mathrm{T}]$, demonstrate that the FCC $\rightarrow$ HCP transition occurs. (i) The enlarged image of the red rectangle in (h) shows the ABABAB HCP stacking.

previous studies [5,39], which is attributed to the combined action of dislocation motion and nanoscale twinning. The onset of necking at $77 \mathrm{~K}$ is delayed as DT brings in a new stage in the strain-hardening rate, which would otherwise decay too fast with increasing strain, resulting in earlier plastic instability.

As shown in Fig. 2c, the strain-hardening rate, $\Theta$, is sustained at a high level to similarly large strains, preventing the onset of necking. This trend is remarkable, because $\mathrm{d} \sigma / \mathrm{d} \varepsilon$ increases apparently with temperature decrease, so as to keep up with the fast rising flow stress $(\sigma)$. At $4.2 \mathrm{~K}$, the easier activation of deformation twinning appears to help elevate the $\Theta$ starting from relatively small strains (the inset in Fig. 2c), largely offsetting the rise in the flow stress from highertemperature levels to prolong the tensile elongation.

\section{Twinning deformation and FCC $\rightarrow \mathrm{HCP}$ transition}

Abundant twin boundaries further improve the strength and ductility, while the triple-twins in the sample (marked by the red triangle in Fig. 6e) strongly refine the grains and block the dislocation motion. As we know, decreasing temperature also could restrict the dislocation movement. These strongly confined dislocations are obviously harmful to the ductility, which is why the ductility at $4.2 \mathrm{~K}$ is relatively shorter than that at $77 \mathrm{~K}$.

The SFE of the CoCrFeNi alloy can be as low as $3.5 \mathrm{~mJ} \mathrm{~m}^{-2}$ [40], facilitating the formation of abundant 
twins at the liquid-helium temperature. Moreover, as shown in Fig. 6g, the typical bright-field STEM image and SAED pattern of $[110]_{\mathrm{FCC}} \|[11 \overline{2} 0]_{\mathrm{HCP}}$ (inset in Fig. $6 \mathrm{~g}$ ) indicate the twinning and HCP phase. The atoms structure was further characterized by the high-resolution STEM. As shown in Fig. 6h, i, many high-density defects, such as nano-twinning, stacking faults, and HCP stacking, could be produced at $4.2 \mathrm{~K}$. These features demonstrate that the FCC $\rightarrow$ HCP transition occurs in the HEA under the tension test, which only appears in the high-pressure condition in previous study [41]. The combined effect of the predominant twinning deformation and FCC $\rightarrow$ HCP phase transformation results in the superior mechanical properties of $\mathrm{CoCrFeNi}$ at $4.2 \mathrm{~K}$.

\section{Serration mechanism and the difference between CoCrFeNi and stainless steel}

Serrated deformation often exists in deformed metals and alloys [42-45], and the possible origins include the plastic-slip instability, deformation twins, stress-induced phase transformation, recrystallization, dynamic strain aging, and adiabatic shearing. In $4.2 \mathrm{~K}$ case, the highdensity deformation twins and a few HCP phases undoubtedly indicate that the joint action of them contribute to the serration behavior.

The fractal dimension $D$ of the serrations is 1.23 at $4.2 \mathrm{~K}$ and 1.22 at $20 \mathrm{~K}$. These results are in accordance with the high-resolution STEM. The joint effect of dislocations motion (the one-dimensional linear defect) with the two-dimensional defects (stacking faults and twinning) and three-dimensional phase transition leads to the fractal dimension equal to nearly 1.23 at $4.2 \mathrm{~K}$.

The largest Lyapunov exponent, $\lambda$, at 4.2 and $20 \mathrm{~K}$ are positive, which indicates that the dynamic behavior of serrations is unstable. The $\lambda$ at $20 \mathrm{~K}$ is smaller than that at $4.2 \mathrm{~K}$, which means that the serration at $20 \mathrm{~K}$ is relatively stable, compared with the serration at $4.2 \mathrm{~K}$. As shown in Fig. $6 \mathrm{~h}$, i, the FCC $\rightarrow$ HCP phase transition occurs at $4.2 \mathrm{~K}$. This phase transition will lead to the dynamical evolution of the serration unstable, well consistent with the results of the largest Lyapunov exponent.

The profuse deformation twinning and the effective storage of the high-density twin boundaries at $4.2 \mathrm{~K}$ will contribute to strain hardening, sustaining a high enough $\Theta$ (the inset of Fig. 2c) for the elongation. Note that the tiny phase transformation is activated in our samples after the tension test at $4.2 \mathrm{~K}$. Thus, we deduce that both DT and phase transformation play a crucial role in the serration formation. Nevertheless, it is difficult to precisely confirm the quantity of the HCP phase as the phase transition only occurs in the localized high stress/ strain zone. This trend is somewhat different from the $316 \mathrm{LN}$ stainless steel. In $316 \mathrm{LN}$, FCC phase is nonmagnetic and martensitic phase is magnetic. Hence, the martensitic phase fraction could be measured precisely through measuring the magnetic properties before and after tensile test at $4.2 \mathrm{~K}$ [2]. The results show the martensitic phase transformation in 316LN stainless steel occuring largely (approximate 20\%) at very low temperatures, which also definitely witnesses that the high-entropy effect could restrict the phase transition. While phase transformation can induce plasticity (TRIP) $[46,47]$, crack initiation may occur at the martensiteaustenite interfaces, bringing in an extra factor that could limit the ductility (e.g., of TRIP steels). The FCC $\rightarrow$ HCP transition could further strengthen this alloy. However, the combined effect of the confined dislocations at low temperatures, only a small fraction of HCP phase formed during deformation, and the crack initiation at phase interfaces resulted in the sharp decline of the ductility below $77 \mathrm{~K}$. The HCP structure in this CoCrFeNi HEA formed via the glide of Shockley partial dislocations on every other $\{111\}$ plane in the FCC matrix. Similar phase transition also occurs at $77 \mathrm{~K}$ in $\mathrm{CoCrFeNi}$ and $\mathrm{CoCrNi}$ alloys $[48,49]$, which indirectly confirms this point.

\section{CONCLUSION}

In this study, the low-SFE FCC CoCrFeNi HEA exhibits an excellent combination of high strength and high ductility at extremely low temperatures. The lower SFE of $\mathrm{CoCrFeNi}$ at the liquid-helium temperature directly facilitates the formation of abundant twins. The deformation twinning derived from the FCC $\rightarrow \mathrm{HCP}$ phase transformation enables the highly-effective-defects (twin boundaries, phase interfaces, and dislocations) storage, microstructure refinement (intersecting twins and subdivision of grains), and therefore, strain hardening. Hence, such HEAs are promising candidates for applications at extremely low temperatures. In addition, the dynamical analyses of serrations at 4.2 and $20 \mathrm{~K}$ show that the evolution of stress signals is unstable, which attributes to the FCC $\rightarrow \mathrm{HCP}$ phase transformation. It also witnesses that the HCP phase is more stable than the FCC phase in this extreme condition under the localized highstress state.

Received 16 September 2018; accepted 9 November 2018; published online 6 December 2018

1 Reed RP, Clark AF. Materials at low temperatures. American 
Society for Metals, Ohio, 1983

2 Yang $\mathrm{H}$, Huang $\mathrm{C}, \mathrm{Wu} \mathrm{Z}$, et al. Analysis on the structural transformation of ITER TF conductor jacket tube. Adv Eng Mater, 2015, 17: 305-310

3 Ogata T, Nagai K, Ishikawa K. Vamas tests of structural materials at liquid helium temperature. In: Reed RP, Fickett FR, Summers LT, Stieg M (eds.). Advances in Cryogenic Engineering Materials. Boston: Springer, 1994, 1191-1198

4 Wang $\mathrm{Y}, \mathrm{Ma} \mathrm{E}$, Valiev $\mathrm{R}$, et al. Tough nanostructured metals at cryogenic temperatures. Adv Mater, 2004, 16: 328-331

5 Gludovatz B, Hohenwarter A, Catoor D, et al. A fracture-resistant high-entropy alloy for cryogenic applications. Science, 2014, 345: 1153-1158

6 Gludovatz B, Hohenwarter A, Thurston KVS, et al. Exceptional damage-tolerance of a medium-entropy alloy $\mathrm{CrCoNi}$ at cryogenic temperatures. Nat Commun, 2016, 7: 10602

7 Jo YH, Jung S, Choi WM, et al. Cryogenic strength improvement by utilizing room-temperature deformation twinning in a partially recrystallized VCrMnFeCoNi high-entropy alloy. Nat Commun, 2017, 8: 15719

8 Deng Y, Tasan CC, Pradeep KG, et al. Design of a twinninginduced plasticity high entropy alloy. Acta Mater, 2015, 94: 124133

9 Laplanche G, Kostka A, Horst OM, et al. Microstructure evolution and critical stress for twinning in the CrMnFeCoNi high-entropy alloy. Acta Mater, 2016, 118: 152-163

10 Zhu YT, Liao XZ, Srinivasan SG, et al. Nucleation and growth of deformation twins in nanocrystalline aluminum. Appl Phys Lett, 2014, 85: 5049-5051

11 Blewitt TH, Coltman RR, Redman JK. Low-temperature deformation of copper single crystals. J Appl Phys, 1957, 28: 651-660

12 Zhu YT, Liao XZ, Wu XL. Deformation twinning in nanocrystalline materials. Prog Mater Sci, 2012, 57: 1-62

$13 \mathrm{Wu} \mathrm{Z}$, Bei H, Pharr GM, et al. Temperature dependence of the mechanical properties of equiatomic solid solution alloys with face-centered cubic crystal structures. Acta Mater, 2014, 81: 428441

14 Liu B, Wang J, Liu Y, et al. Microstructure and mechanical properties of equimolar FeCoCrNi high entropy alloy prepared via powder extrusion. Intermetallics, 2016, 75: 25-30

15 Huo W, Zhou H, Fang F, et al. Strain-rate effect upon the tensile behavior of CoCrFeNi high-entropy alloys. Mater Sci Eng-A, 2017, 689: 366-369

16 Huo W, Fang F, Zhou H, et al. Remarkable strength of CoCrFeNi high-entropy alloy wires at cryogenic and elevated temperatures. Scripta Mater, 2017, 141: 125-128

17 Zhang Y, Zuo TT, Tang Z, et al. Microstructures and properties of high-entropy alloys. Prog Mater Sci, 2014, 61: 1-93

18 Miracle DB, Senkov ON. A critical review of high entropy alloys and related concepts. Acta Mater, 2017, 122: 448-511

19 Lyu Z, Fan X, Lee C, et al. Fundamental understanding of mechanical behavior of high-entropy alloys at low temperatures: A review. J Mater Res, 2018, 33: 2998-3010

20 Laktionova MA, Tabchnikova ED, Tang Z, et al. Mechanical properties of the high-entropy alloy $\mathrm{Ag}_{0.5} \mathrm{CoCrCuFeNi}$ at temperatures of $4.2-300 \mathrm{~K}$. Low Temperature Phys, 2013, 39: 630-632

21 Qiao JW, Ma SG, Huang EW, et al. Microstructural characteristics and mechanical behaviors of $\mathrm{AlCoCrFeNi}$ high-entropy alloys at ambient and cryogenic temperatures. MSF, 2011, 688: 419-425
22 Zhang W, Liaw PK, Zhang Y. Science and technology in highentropy alloys. Sci China Mater, 2018, 61: 2-22

23 Li DY, Zhang Y. The ultrahigh charpy impact toughness of forged $\mathrm{Al}_{x} \mathrm{CoCrFeNi}$ high entropy alloys at room and cryogenic temperatures. Intermetallics, 2016, 70: 24-28

24 Vicsek T. Fractal growth phenomena. Singapore: World Scientific, 1992

25 Chen C, Ren J, Wang G, et al. Scaling behavior and complexity of plastic deformation for a bulk metallic glass at cryogenic temperatures. Phys Rev E, 2015, 92: 012113

26 Chen S, Yu L, Ren J, et al. Self-similar random process and chaotic behavior in serrated flow of high entropy alloys. Sci Rep, 2016, 6: 29798

27 Ren JL, Chen C, Wang G, et al. Dynamics of serrated flow in a bulk metallic glass. AIP Adv, 2011, 1: 032158

28 Ren JL, Chen C, Liu ZY, et al. Plastic dynamics transition between chaotic and self-organized critical states in a glassy metal via a multifractal intermediate. Phys Rev B, 2012, 86: 134303

29 Guo X, Xie X, Ren J, et al. Plastic dynamics of the $\mathrm{Al}_{0.5} \mathrm{CoCrCuFeNi}$ high entropy alloy at cryogenic temperatures: Jerky flow, stair-like fluctuation, scaling behavior, and non-chaotic state. Appl Phys Lett, 2017, 111: 251905

30 Takens F. Detecting strange attractors in turbulence. In: Rand D, Young LS (eds). Dynamical Systems and Turbulence, Warwick 1980. Lecture Notes in Mathematics, vol 898. Heidelberg: Springer, 1981, 366-381

31 Packard NH, Crutchfield JP, Farmer JD, et al. Geometry from a time series. Phys Rev Lett, 1980, 45: 712-716

32 Fraser AM, Swinney HL. Independent coordinates for strange attractors from mutual information. Phys Rev A, 1986, 33: 11341140

33 Cao L. Practical method for determining the minimum embedding dimension of a scalar time series. Physica D-Nonlinear Phenomena, 1997, 110: 43-50

34 Wolf A, Swift JB, Swinney HL, et al. Determining Lyapunov exponents from a time series. Physica D-Nonlinear Phenomena, 1985, 16: 285-317

35 http://www.copper.org/resources/properties/144_8/

36 Estrin Y, Isaev NV, Lubenets SV, et al. Effect of microstructure on plastic deformation of $\mathrm{Cu}$ at low homologous temperatures. Acta Mater, 2006, 54: 5581-5590

37 Tobler RL, Berger JR, Bussiba A. Long-crack fatigue thresholds and short crack simulation at liquid helium temperature. In: Fickett FR, Reed RP (eds.). Advances in Cryogenic Engineering: Materials. Boston: Springer, 1992, 159-166

38 Das A, Tarafder S. Geometry of dimples and its correlation with mechanical properties in austenitic stainless steel. Scripta Mater, 2008, 59: 1014-1017

39 Otto F, Dlouhý A, Somsen C, et al. The influences of temperature and microstructure on the tensile properties of a CoCrFeMnNi high-entropy alloy. Acta Mater, 2013, 61: 5743-5755

40 Huang S, Li W, Lu S, et al. Temperature dependent stacking fault energy of FeCrCoNiMn high entropy alloy. Scripta Mater, 2015, 108: $44-47$

41 Zhang $\mathrm{F}$, Wu $\mathrm{Y}$, Lou $\mathrm{H}$, et al. Polymorphism in a high-entropy alloy. Nat Commun, 2017, 8: 15687

42 Pustovalov VV. Serrated deformation of metals and alloys at low temperatures. Low Temperature Phys, 2008, 34: 683-723

43 Zhang Y, Liu JP, Chen SY, et al. Serration and noise behaviors in materials. Prog Mater Sci, 2017, 90: 358-460 
44 Antonaglia J, Xie X, Tang Z, et al. Temperature effects on deformation and serration behavior of high-entropy alloys (HEAs). JOM, 2014, 66: 2002-2008

45 Tirunilai AS, Sas J, Weiss KP, et al. Peculiarities of deformation of CoCrFeMnNi at cryogenic temperatures. J Mater Res, 2018, 33: 3287-3300

46 Grässel O, Krüger L, Frommeyer G, et al. High strength Fe-Mn(Al, Si) TRIP/TWIP steels development-properties-application. Int J Plast, 2000, 16: 1391-1409

47 Li Z, Pradeep KG, Deng Y, et al. Metastable high-entropy dualphase alloys overcome the strength-ductility trade-off. Nature, 2016, 534: 227-230

48 Lin Q, Liu J, An X, et al. Cryogenic-deformation-induced phase transformation in an FeCoCrNi high-entropy alloy. Mater Res Lett, 2018, 6: 236-243

49 Miao J, Slone CE, Smith TM, et al. The evolution of the deformation substructure in a Ni-Co-Cr equiatomic solid solution alloy. Acta Mater, 2018, 132: 35-48

Acknowledgements This work was supported in part by the National Natural Science Foundation of China (51471025, 51671020, 51471024 and 11771407); the Department of Energy (DOE), Office of Fossil Energy, National Energy Technology Laboratory (DE-FE-0011194) with the program manager Dr. J. Mullen; the support from the US Army
Research Office project (W911NF-13-1-0438) with the program managers Drs. M.P. Bakas, S.N. Mathaudhu, and D.M. Stepp; the support from the National Science Foundation (DMR-1611180 and 1809640) with the program directors, Drs G. Shiflet and D. Farkas. We also thank Prof. WH Wang at the Institute of Physics, Chinese Academy of Sciences, Prof. XL Wang at the City University of Hong Kong, and Prof. K Samwer at the University of Göttingen for their insightful and constructive comments on this paper. We appreciate Dr. RJ Huang, SF Li, and Z Zhang at the Key Laboratory of Cryogenics, Technical Institute of Physics and Chemistry, Chinese Academy of Sciences, for their help on mechanical tests.

Author contributions Zhang Y conceived the overall project. Liu J, He $\mathrm{Z}$, and $\mathrm{Li} \mathrm{L}$ performed the experiments. He $\mathrm{Z}$ conducted the TEM characterization. Liao X, Lin Q, and An X performed the STEM characterization. Ren J, Guo X and Yu L carried out the calculations of the serration feature. Lin J, Guo X, He Z, Liaw P, Ren J and Zhang Y wrote the paper. All authors discussed the results and commented on the manuscript.

Conflict of interest These authors declare no conflict of interest.

Supplementary information online version of this paper.
Supporting data are available in the 

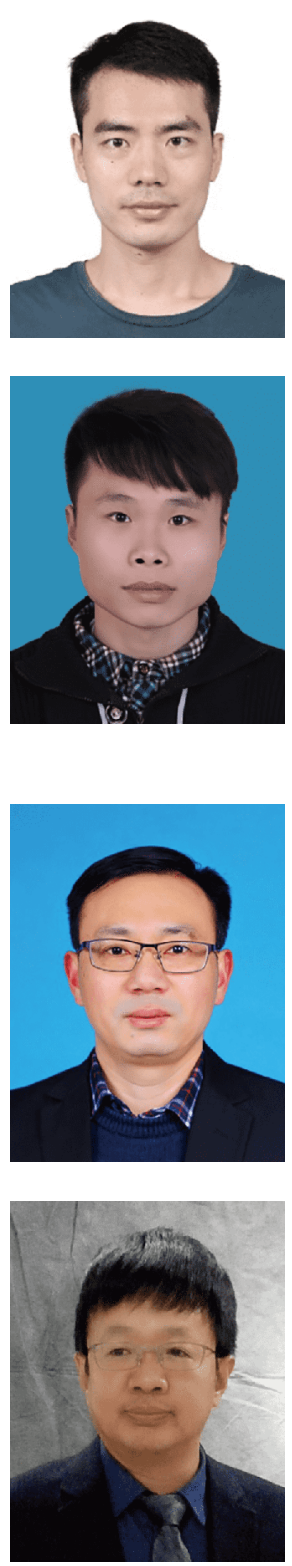

Junpeng Liu received his PhD degree from the University of Science and Technology Beijing (USTB) in 2018. Currently, he is a Post-doctoral Fellow at the State Key Laboratory of Non-linear Mechanics, Institute of Mechanics, Chinese Academy of Sciences. His current research interest focuses on the deformation and strengthening/ductilization of advanced structural materials, such as high-entropy alloys, and high-performance steels.

Xiaoxiang Guo received his Master's degree from Zhengzhou University in 2017. Currently, he is a PhD candidate at the School of Mathematics and Statistics, Zhengzhou University, China. His current research interest focuses on the mathematical applications in materials science.

Zhanbing He received his PhD degree in materials science from Dalian University of Technology in 2005. He did scientific research at Stockholm University, Swiss Federal Institute of Technology in Lausanne (EPFL), and Ecole Polytechnique from 2005 to 2013. He joined the State Key Laboratory for Advanced Metals and Materials at the University of Science and Technology Beijing in 2013 as a full Professor. His research interest is in TEM, quasicrystals, and high-entropy alloys.

Yong Zhang received his PhD degree in materials science from USTB in 1998. He did post-doctoral work at the Institute of Physics, Chinese Academy of Sciences. Then, he joined NUS-MIT SMA in 2000. He has been a Professor of materials science at USTB since 2004. His research interest is in high-throughput preparation of high-entropy alloys, and theory prediction of the phase formation for the multicomponent materials.

\section{超低温环境下亚稳态 $\mathrm{CoCrFeNi}$ 高熵合金的优异塑性和锯齿流变行为}

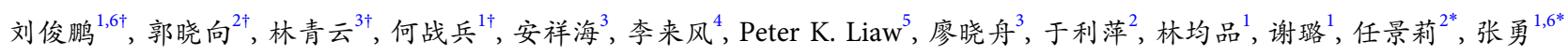

摘要 低温环境下, 位错的运动受到限制而导致极少数的金属和合金能保持优异的力学性能, 尤其是塑性. 本文研究了具有面心立方结构 的 $\mathrm{CoCrFeNi}$ 高熵合金的超低温服役, 发现其在低温环境下具有优异的综合性能. $4.2 \mathrm{~K}$ 时的拉伸强度达到 $1260 \mathrm{MPa}$, 同时延伸率达到 $62 \%$, 展现出极强的低温应用潜力; 超低温环境下, 高熵合金极低的层错促进了变形孪晶的产生, 使其表现出高强高韧的优异力学性能. 此外, 在 液氦环境下, 该合金中FCC-HCP 的相转变和锯齿流变行为使得合金在 $77 \mathrm{~K}$ 以下温度的塑性降低; 同时, 关于锯齿特征的动态模型分析证实 由于相变行为的出现导致该合金中锯齿行为的不稳定特点. 液氦环境下, 大量的变形孪晶和相变行为的共同作用导致了较高的应变硬化 率, 从而使高熵合金的塑性变形维持在较高的应力水平, 并且形成了锯齿特征. 